\title{
Theoretical Consideration on Plasma Volume Determination
}

\author{
Atsuo NAKANISHI; M.D.
}

From the results of experinent in which the disappearance curve was observed for 8 hours or longer after the dye injection, a theory of multiple volume compartments system has been derived, assuming that dye moves in the plasma according to dye concentration difference between various compartments. It seems to be then that, even if the dilution curve had been exponential, it would not represent the true disappearance curve seen after the uniform mixing of dye with plasma. This assumption was evidently proven in the present study of the dilution curve covering a period of 10 minutes to $1-2$ hours of patients with congestive heart failure.

TN recent years, the method of plasma volume determination, using the blue azo dye "T-1824," originated by Gregersen and his associates" and later applied for clinical use by Gibson and Evans" has been used commonly. The method of calculation for this plasma volume determination depends upon the amount of the dye injected and its concentration at the time when all the injected dye was assumed to be uniformly mixed with the blood strcam. To obtain such a dye concentration, scveral cxtrapolation mcthods from a certain portion of T-1824 time-concentration curve (or dilution curve) have been advocated. But the values so determined cast some doubt upon whether they actually indicate the circulating plasma volume or total plasma volume. To answer this question, in 1951, the author has already reported a hypothesis derived by analysis of the factors shaping the T-1824 time-concentration curve. ${ }^{3)}$ In this paper, the author intends, therefore, to introduce both this hypothesis and results ${ }^{4}$ developed later from it to the readers for the explanation of the significance of values of plasma volume. The first step to understand this hypothesis clearly is to know the causes by which the concentration of dye injected into the blood stream is decreased with the time.

Dilution Process after the Dye Injection-

Dye mixing with blood stream: It is well known that when samples are taken at 1 to 4 minute intervals over a period of 30 minutes or longer after the injection of the dye in normal subjects, the dye concentration of successive samples reaches the peak within 10 minutes. This is followed by a rapid fall of the dye concentration at first, then a gradual decrease at about a constant rate occurs. According to Gibson and Evans, ${ }^{2}$ the initial rapid fall in con-

From the Second Department of Internal Medicine, Faculty of Medicine, University of Tokyo. 
centration was considered to be due to mixing of dye with the blood stream, and this portion of the time-concentration curves was termed as the mixing curve, and the subsequent portion in which the fall in the concentration is gradual and constant, was considered to be due to the removal of the dye from the blood stream principally by phagocytic function of the reticulo-endothelial system and designated as the disappearance slope. The tangent point of these two curves was called " mixing time." The mixing time in normal individual was reported seven and half minutes by Gibson and Evans, ${ }^{2} 9$ minutes by Gregersen ${ }^{51}$ and in the $\operatorname{dog} 4$ to 6 minutes by Miller, ${ }^{6}$ and within 5 minutes by Gilder ${ }^{7)}$ and Lawson. ${ }^{8}$

To confirm these data that complete mixing is achieved within 10 minutes after dye injection in man, hepatic vein catheterization was made to obtain simultaneous dye concentration curves of hepatic and antecubital veins. As shown in Table I, ${ }^{4}$ a total of 39 subjects consisting of 11 normal persons, 18

Table I. Comparison of Plasma Concentrations of T-1824 in the Peripheral Vein and the Hepatic Vein

\begin{tabular}{|c|c|c|c|c|c|c|c|}
\hline \multirow{2}{*}{ Group } & \multirow{2}{*}{$\begin{array}{c}\text { No. of } \\
\text { cases }\end{array}$} & \multicolumn{2}{|c|}{$\begin{array}{c}\text { No. with agreement } \\
\text { with less than } 5 \% \text { of } \\
\text { experimental error limits }\end{array}$} & \multirow{2}{*}{$\begin{array}{l}\text { No. without } \\
\text { agreement } \\
\text { at } 30 \text { min. } \\
\text { or more }\end{array}$} & \multicolumn{2}{|c|}{$\begin{array}{c}\text { No. with agreement } \\
\text { with less than } 3 \% \text { of } \\
\text { experimental error limits }\end{array}$} & \multirow{2}{*}{$\begin{array}{l}\text { No. without } \\
\text { agreement } \\
\text { at } 30 \text { min. } \\
\text { or more }\end{array}$} \\
\hline & & $\begin{array}{l}\text { within } 10 \\
\text { minutes }\end{array}$ & $\begin{array}{l}\text { in a period } \\
\text { of } 10 \text { to } \\
30 \text { min. }\end{array}$ & & $\begin{array}{l}\text { within } 10 \\
\text { minutes }\end{array}$ & $\begin{array}{l}\text { in a period } \\
\text { of } 10 \text { to } \\
30 \text { min. }\end{array}$ & \\
\hline Normal & 11 & 3 & 6 & 2 & 2 & 7 & 2 \\
\hline Liver disease & 18 & 2 & 4 & 12 & 0 & 6 & 12 \\
\hline Other disease & 10 & 2 & 8 & 0 & 1 & 7 & 2 \\
\hline \multirow{2}{*}{ Total } & \multirow{2}{*}{39} & 7 & 18 & \multirow{2}{*}{14} & 3 & 20 & \multirow{2}{*}{16} \\
\hline & & \multicolumn{2}{|c|}{25} & & \multicolumn{2}{|c|}{23} & \\
\hline
\end{tabular}

Total cases showed higher T-1824 plasma concentration in the peripheral vein.

patients with liver diseases and 10 patients with diseases other than circulatory disturbances were cxamined. With an error of less than $5 \%, 7$ cases of these had the same concentration in the two veins within 10 minutes after the injection of dye, 18 had the same concentration in a period of 10 to 30 minutes, and the remaining 14 had always higher concentration in the antecubital vein than in the hepatic vein even after 30 minutes. It may be inferred therefore, that mixing is not always completed in 30 minutes even for the subjects without hemodynamic disturbances.

Disappearance of dye from the blood stream: The removal of the dye from the blood is mainly by phagocytic action of reticulo-endothelial system ${ }^{9}$ or staining in tissues. It also appears in the lymph ${ }^{10) 111}$ and bilc. ${ }^{11}$ According to the extraction method, it may be found even in the urine. ${ }^{12)}$ In thoracic lymph the dye appeared 15 to 30 minutes after the administration of dye, 
concentration of which increased gradually, amounting to 20 to $40 \%$ of the plasma level in 2 hours. This observation was confirmed later by Schultz ${ }^{13)}$ in dogs employing the labelled albumin which has been widely applied for estimation of the plasma volume. From these observations, the possibility can not be denied that as the lymph flow is too slow, the dye may have been already removed from the blood stream earlier than 10 minutes. In cervical lymph, the dye also appeared in a similar pattern to that of the thoracic duct, but its concentration was one-half of that of the thoracic duct. ${ }^{10}$ Therefore, it is evident that a total amount of dye removed into the lymph was not small in quantity in spite of its low concentration in the lymph. In addition, it has been demonstrated that the dye appeared in the bile in 30 minutes, concentration of which reached the maximum at 60 to 90 minutes, and then decreased gradually parallel with that of the plasma. If the dye was injected intravenously in succession, the dye level of bile rose in accordance with the plasma level. ${ }^{11}$ It was already mentioned that even in the urine the dye could be detected when the extraction method is employed. It is also well known that analogous dye to T-1824, congo red, is excreted into urine in large quantities in patients with amyloidosis and those with nephrosis. ${ }^{14}$ ) Fig. 1. shows that the considerably large quantity of T-1824 dye was excreted

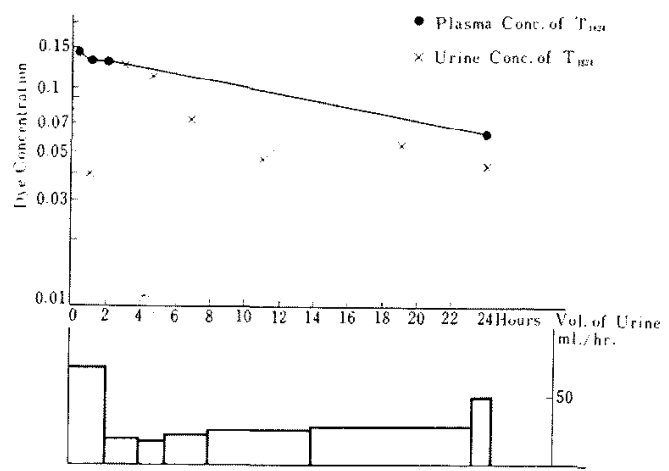

Fig. 1. Appearance of $\mathrm{T}-1824$ in the urine of a patient with nephrosis.

in the urine of a patient with nephrosis, and its concentration is almost equal to the plasma level at a period of 2 to 4 hours after intravenous administration. In summary, there is reason enough to assume that the phase of the disappearance slope indicates not only disappearance but also mixing of the dye from or with the blood stream.

Extrapolation Method of the Disappearance Slope-

Extrapolation method is the means by which a dye concentration is obtained assuming all the injectcd dyc wcre completely mixed with the circulating blood without loss of any dye. In practice, this method was done by extending the disappearance slope backward to the time of dye injection.

Calculation of the plasma volume based upon the extrapolation method 
was first suggested by Erlanger. ${ }^{15)}$ Sunderman ${ }^{16)}$ extrapolated with a straight line from the values of the dye concentration at 30-, 60-, and 90-minutes, Gibson and Evans ${ }^{2 /}$ extrapolated from the linear portion of disappearance slope by a straight line, and Gregersen ${ }^{11}$ and Price ${ }^{17}$ ) extrapolated with exponential curve. However, Hahn and his associates ${ }^{18}$ described that the time-concentration curve could be divided into 3 phases when the logarithm of the plasma concentration of the dye was plotted against time. Miller, ${ }^{6}$ likewise, divided the time-concentration curve into 3 phases and obtained the plasma volume by extrapolating the 2 nd phase in an exponential manner. The fact that various extrapolation methods have been advocated by several investigators means evidently that the mixing and disappearance portions of the time-concentration curve blend so gradually that it is difficult to decide exactly at what point the disappearance curve begins; that "disappcarance curve," strictly speaking, seems to be a straight line neither on a linear nor semilogarithmic plot.

Theoretical Analysis of Disappearance Curve-

To elucidate the complexity of the disappearance curve, the experiments were done by tracing the time-concentration curves of the dye precisely up to 30-100 hours. It was found that in 17 normal individual, 23 dogs, 31 rabbits and 24 cardiacs with or without congestive heart failure, the curve observed from 10 minutes to 1-2 hours after intravenous injection of the dye was expressed as one exponential curve with less than $5 \%$ of error limits. Whereas it was found that the curve observed from 10 minutes to 7-8 hours was expressed as a sum of two cxponcntial curves, and in one case of a dog and a rabbit, that taken from 10 minutes up to 30-100 hours as a sum of three exponential curves. Therefore, the disappearance curve was summarized mathematically as the following experimental equation:

$$
\mathrm{C}_{\mathbf{1}}=\sum_{\mathrm{i}=1}^{\mathrm{n}} \mathrm{K}_{\mathrm{i}} \mathrm{e}^{-\mathrm{xit}}
$$

where $\mathrm{C}_{1}$ is the concentration of the dye at any time, $t ; \mathrm{K}_{\mathrm{i}}$ and $\mathrm{x}_{\mathrm{i}}$ are constants, $\mathrm{n}$ is 1,2 , or 3 .

The same formula as equation (1)* was derived theoretically by the author from an assumption that the plasma of volume $V$ was a system consisting of $n$ compartments separated by boundaries from one another, according to the degree of time required for the plasma to be uniformly mixed with the dye. And it was conculuded that the disappearance curve was by no means both experimentally and theoretically either a straight line or a simple one exponential curve. Based on this theory, the dye concentration at the time of injection, $\mathrm{C}_{10}$, is given by setting $\mathrm{t}=0$ in equation (1). In the special case of $\mathrm{n}-2$, not only plasma volume $V$ can be calculated, but also the volume of 2 compartments: the volume of rapidly circulating plasma, $V_{1}$, and that of sluggishly moving or stagnant one, $V_{2}$. In normal subjects the ratio of $V_{1}$ to $V$ was

* The derivation of this and subsequent equations will be found in Appendix. 
$91 \pm 3 \%$, and in patients with congestive heart failure, it was $83-61 \%$. These results were interpreted to show a fact that the latter had more sluggish plasma than the former. Here, the sluggishly moving plasma denoted the slowly moving and stationary plasma in the minute vessels. However, in such cases, it was necessary to trace the time-concentration curve as long as 7 to 8 hours. Because of this handicap, equation (1) is usually employed as $\mathbf{n}=1$. In this case, equation (1) becomes:

$$
\mathrm{C}_{1}=\mathrm{C}_{1 \eta} \mathrm{e}^{-\mathrm{k}_{0}{ }^{\mathrm{t}}}
$$

therefore,

$$
\text { plasma volume } V=\frac{M}{\mathrm{C}_{10}}
$$

where $\mathrm{C}_{1}$ is the concentration of the dye at any time, $t, \mathrm{C}_{10}$ is the concentration of the dye at the time of the injection, $M$ is amount of the injected dye, and $\mathrm{k}_{\mathrm{o}}^{\prime}$ is the disappearance coefficient.

Analysis of the Disappearance Coefficient $\mathrm{k}_{\mathrm{o}}^{\prime}-$

If the plasma with a definite concentration of the dye flows without friction, and flows repeatedly at an uniform flow rate in the loop-pipe of volume $\mathrm{V}$, and the dye leaks out from a special plane supposed to be in the loop-pipe, the rate of decrease in the number of units of dye, $q_{1}$, in the loop-pipe at any time, $t$, is dependent upon flow rate $F$ and the concentration $\mathrm{C}_{1}$ at the time of $\mathrm{t}$. Therefore,

$$
\frac{\mathrm{dq}}{\mathrm{dt}}=-\alpha \mathrm{C}_{1} \mathrm{~F}
$$

where $\alpha$ is constant relating to the efficiency of the plane. Dividing both sides of equation (3) by $\mathrm{V}$, the rate of change in concentration is given as:

$$
\frac{\mathrm{dC}_{1}}{\mathrm{dt}}=-\alpha \frac{\mathrm{F}}{\mathrm{V}} \mathrm{C}_{1}
$$

which on integration

$$
\mathrm{C}_{1}=\mathrm{C}_{10} \mathrm{e}^{-\alpha \frac{\mathrm{F}}{\mathrm{V}} \mathrm{t}}
$$

where $\mathrm{C}_{10}$ is the concentration before the leakage of the dye.

From equations (2) and ( $\left.3^{\prime}\right)$, it follows that, if the equation (2) expresses the "disappearance curve due to constant rate of concentration decrease inscribed solely to the removal of the dye from blood stream occurring after the completion of uniform mixing with plasma of flow rate $F$, disappearance coefficient $k^{\prime}{ }_{0}$ should be proportional to the ratio of plasma flow, $F$, to plasma volume, $\mathrm{V}$, or to the ratio of blood flow to blood volume.

For practical purposes, cardiac output may probably be applied to the blood flow, since the greater part of injected dye is mixed with the blood stream into the heart. Thus, in 5 normal individuals and 11 cases with various 
diseases including 6 with congestive heart failure due to valvular lesions, two with pulmonary emphysema, and one case of thyrotoxicosis, nephrosis and splenomegaly, cardiac output was estimated by using the cardiac catheterization technic, and blood volume was determined from the value of plasma volume and hematocrit. The value of plasma volume was calculated by extrapolating the from 10-minute to $1-2$ hour time-concentration curve of T-1824 as one exponential curve. As seen in Fig. 2, the negative correlation between the disappearance coefficient and the ratio of cardiac output to blood volume was small $(\mathrm{r}=0.42)$, but was statistically significant. This was an unexpected result, since it would have been positive.

In Fig. 2, it appears to show that cardiac cases with failure have higher values of $\mathrm{k}_{0}{ }_{0}$ than that of normals. This relation was also presented at different occasion in a great number of cases $^{31}$ (Fig. 3). This finding is illustrated in

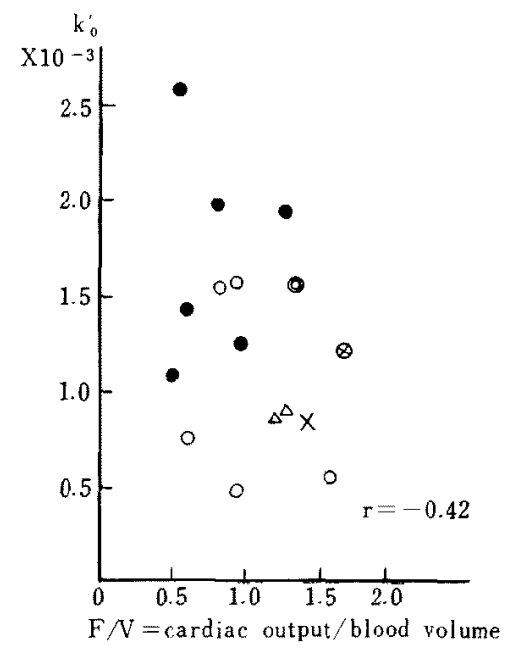

Fig. 2. Correlation of disappearance coefficient $k_{0}^{\prime}$ (ordinate) to cardiac output blood volume ratio (abscissa) in normal subject $\bigcirc$ and in patients with congestive heart failure - with thyrotoxicosis $\Leftrightarrow$, with pulmonary emphysema $\triangle$, with nephrosis $\%$, and with splenomegaly $\oplus$.

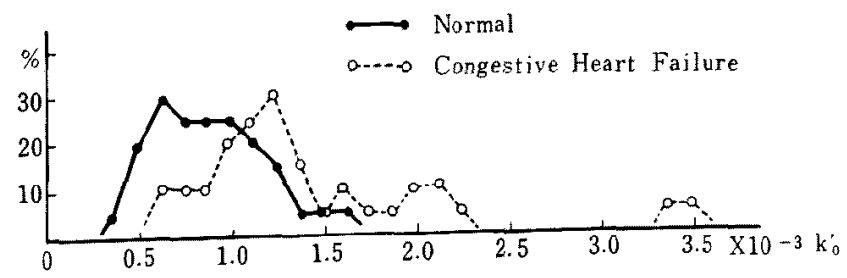

Fig. 3. Frequency distribution of values for $k_{0}^{\prime}$ in normal subjects and in patients with congestive heart failure.

Fig. 4 as a schematic drawing. While the dilution curves of normals decrease rapidly, as the initial mixing for 10-20 minutes, and then fall gradually at 
nearly a constant slow rate of decrease, those of cardiac cases decrease at a rapid rate corresponding to that of initial mixing of normals for as long as 1-2 hours, indicating that the mixing which occurs early in the normals will continue as long as 1-2 hours in cardiac cases.

As illustrated in Fig. 5, in normal subjects, mixing with the stagnant
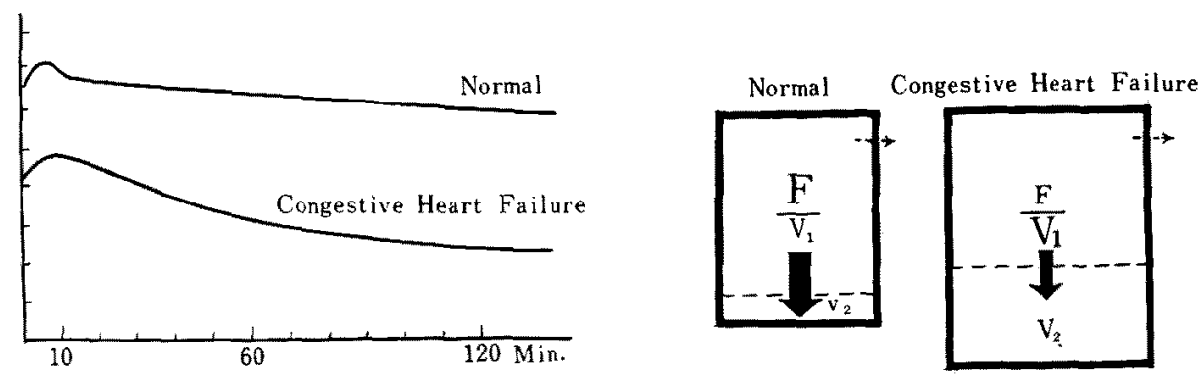

Fig. 4 (Left). Schematic representation of the dilution curve of normal subjects and of patients with congestive heart failure. Ordinate, concentration of dye; and abscissa, time in minutes.

Fig. 5 (Right). Schematic representation of 2 -compartment system in a normal subject and patient with congestive heart failure. $V_{1}$, volume of rapid circulating plasma; $V_{2}$, volume of stagnant plasma : and $F$, minute volume of plasma

plasma occurs so early, because of its relatively small volume, that $\mathrm{k}_{\mathrm{o}}^{\prime}$ nears the "true" disappearance coefficient seen after the uniform mixing with all the plasma in the body, which should be proportional to the rate of cardiac output to the blood volume. On the other hand, in cases with congestive heart failure, mixing is taking place so late up to 1-2 hours, because of lower cardiac output and large volume of stagnant plasma, that $\mathrm{k}^{\prime}$ obecomes to express not only the disappearance of the dye to the outside of the blood vessels, but the dye mixing with stagnant plasma.

For these reasons, $\mathrm{k}_{\mathrm{o}}^{\prime}$ becomes larger in the cases with congestive heart failure than that in normals, notwithstanding that $\mathrm{F} / \mathrm{V}$ is smaller as compared to normals. In retrospect, it was an error to take dilution curve covering from 10 minutes up to $1-2$ hours as "true" disappearance curve, on account of that it had been possible to express it as one exponential curve with less than $5 \%$ of expcrimental error. If the observation time would have been for 7-8 hours, and whereby the dilution curve would have been decomposed into 2 exponential components, and if the corresponding exponential curves of normals and cases with congestive heart failure were compared, such an error should not have happened.

That $\mathrm{k}_{0}^{\prime}$ increases with the rise in $\mathrm{F} / \mathrm{V}$, was proven in normal subjects by the fact that, when $\mathrm{F} / \mathrm{V}$ increased 4 times by epinephrine injection as compared with that in the control period, $\mathrm{k}^{\prime}$ increased 3 times (Fig. 6).

Change in Disappearance Coefficient $\mathrm{k}_{0}^{\prime}$ at the Repeated Determinations of Plasma Volume- 


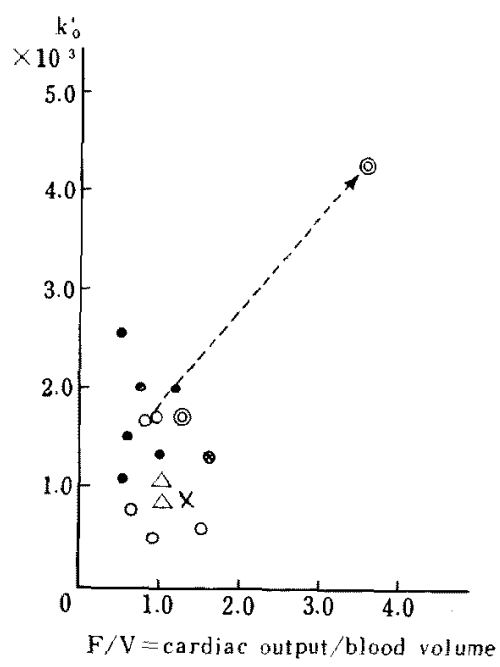

Fig. 6. The change in disappearance coefficient $k^{\prime}$ and cardiac output/blood volume after the administration of epincphrinc.

In 4 men and 5 dogs, the second dose of the dye in the same amount was injected 1 hour after the first injection. In each case, plasma volume was determined by extrapolation of dilution curve covering a period of 10 minutes to 1 hour. All cases except 1 human subject showed the identical values of plasma volume with less than $5 \%$ of error, while $\mathrm{k}_{0}^{\prime}$ was smaller in the second determination than the initial in all cases except 2 dogs.

Since $\mathrm{k}_{\mathrm{o}}^{\prime}$ of the second dilution curve is, as described below, dependent upon $\mathrm{k}_{\mathrm{o}}$ of the first dilution curve and the time of the second injection, it was a natural result for the second $k^{\prime}$ o to be smaller than the initial $k_{0}^{\prime}$ under the conditions examined. Therefore, it must be considered carefully to estimate the function of the reticulo-endothelial system from the change in $\mathrm{k}^{\prime}$ o as already reported. ${ }^{19 / 20)}$

Fig. 7 shows the case where the first 1 hour part of dilution curve observed up to 2 hours was superimposed on the subsequent one hour part, assuming that the second injection was done with the same amount of dye. The rate of concentration decrease of the composed curve was smaller than that of the first part of the original curve. This indicates that the degree of mixing with stagnant plasma is different according to the portions (or phases) of one exponential curve; in the last half portion of this, the mixing is performed more completely than in the first portion. Therefore, the rate of concentration decrease of the composed curve becomes smaller by influence of the latter half part of original curve.

Relation between $\mathrm{k}_{0}^{\prime}$ and Plasma Protein-

Rossiter ${ }^{21}$ has emphasized earlier that $\mathrm{k}_{0}^{\prime}$ was in close relation with albumin concentration in plasma, on the ground that T-1824 combines firmly with the plasma albumin. However, the author") could not agree with his 


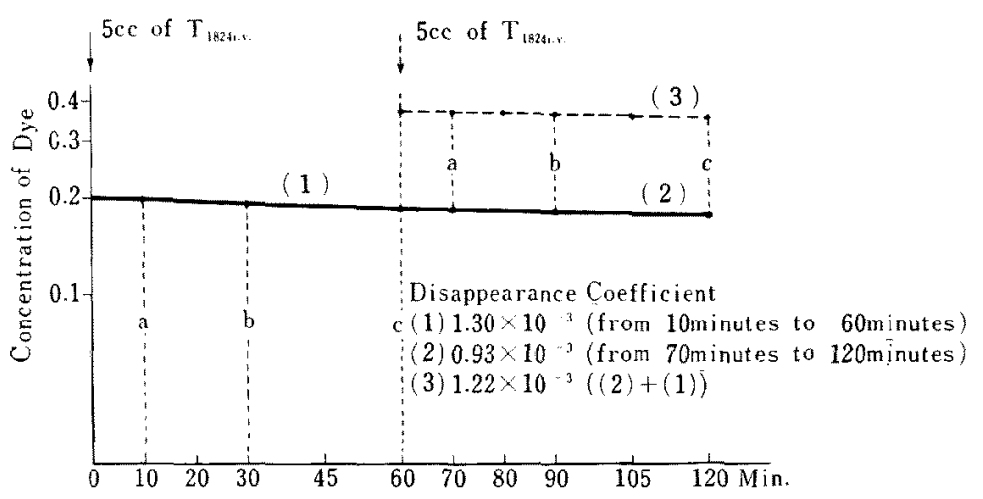

Fig. 7. Comparison of value for the disappearance coefficient $\mathrm{k}_{0}^{\prime}$ observed after the second injection with that observed after the initial injection. The second injection was supposed to have been done with the same dose at one hour after the initial injection.

assertion by the results obtained from 16 cases of human being examined, that $\mathrm{k}^{\prime}$, has no statistically significant correlation with plasma total protein $(\mathrm{r}=-0.17)$, plasma albumin $(\mathrm{r}=+0.001)$, and plasma globulin concentrations $(r=-0.05)$, respectively.

It has been also reported that one molecule of albumin bound with seventy molecules of $\mathrm{T}-1824 .{ }^{22}$ ) According to Rawson, ${ }^{23)}$ the dosage usually used for plasma volume determination, $20-15 \mathrm{mg}$. of $\mathrm{T}-1824$, was said to combine with albumin contained in $89-67 \mathrm{cc}$. of plasma. In addition, the same value of plasma volume was given even when a twenty-fold dye was administered. ${ }^{20}$ These indicate that $\mathrm{k}_{\mathrm{o}}^{\prime}$ has almost no relationship to the concentration of plasma albumin with the dosage usually employed.

In summary, it was found that the dilution curve covering a period of 10 minutes to 1-2 hours showed the disappcarance of the dye from the blood stream and mixing of the dye with the stagnant plasma, even if it presents one exponential curve within the experimental error limits. Consequently, extrapolation of such a dilution curve as one exponential curve comes to measure the volume of the circulating plasma including a part of the stagnant plasma. It was due to the false logic consideration that the sum of at least 2 different exponential curves was expressed as one mean exponential curve. Accordingly, the volume of circulating plasma thus measured should be deemed as the volume of "space." Even though circulating plasma volume is measured by dividing one exponential curve into two different types of exponential curve, it shows the volume of "space" after all.

Comparison of the Plasma Volume Calculated from the Ten-minute Sample with the Results Obtained by Extrapolation of the Dilution Curve as One Exponential Curve-

When the plasma volume calculated from the 10-minute sample, by the commonly used method of Gregersen, was compared with the more accurate values obtained by one exponential extrapolation of the dilution curve in a total of 41 cases including normal individual and patients with various dis- 
Table II. Comparison of Values for Plasma Volume by

Gregersen's 10-minute Method and by Extrapolation

Method of One Exponential Curve

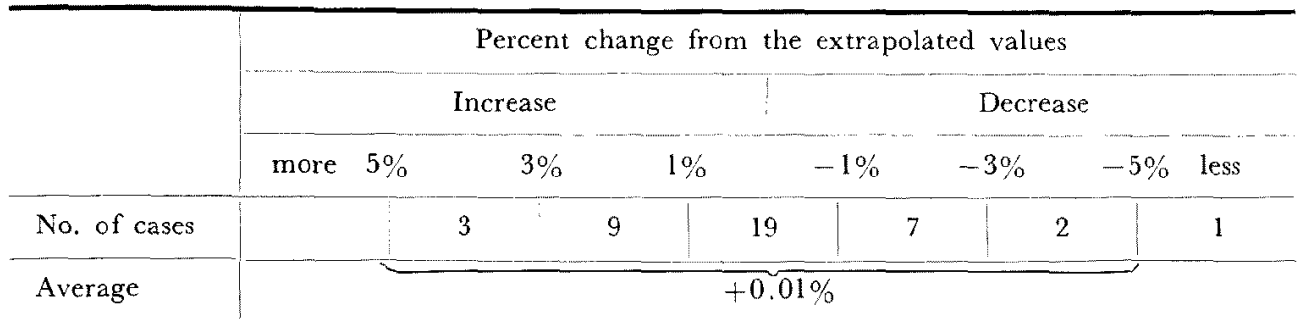

eases, these two instances almost agreed within the experimental error limits, so far as the time of onset of observed curves was limitted to 10 minutes after dye injection (Table II). Therefore, Gregersen's method may be utilized as a simple method in place of the one exponential method, however this method does not represent the true values of total plasma volume, but the values of "space" at 10 minutes.

\section{SuMmary}

(1) A theory has been derived from analysis of the factors shaping the dilution curve in the multiple volume compartments, assuming that injected dye moves in the plasma, according to its concentration difference between the compartments.

(2) From the theoretical analysis of disappearance coefficient, it has been clarified that a) dilution process during a period of 10 minutes to 1-2 hours was governed by the mixing of dye with the plasma and removal of dye from the blood stream, b) during this period mixing was performed completely in a great number of normal individuals, whereas mixing was still in process in some patients with congestive heart failure, c) plasma volume estimated by one exponential extrapolation of dilution curve covering a period of 10 minutes to 1-2 hours was considered as the values of "space," and d) the 10-minute method of Gregersen is useful as a simple method, but the values thus obtained do not represent the true plasma volume.

(3) This theory offers an actual determination of plasma volume and the stagnant plasma volume. This appeared to be very useful clinically in case of congestive heart failure.

\section{Appendix: Derivation of Equations}

As shown in Fig. 8, it was assumed that a system of the total plasma of volume $\mathrm{V}$ could be divided into $\mathrm{n}$-compartment of volume, $\mathrm{V}_{1}, \mathrm{~V}_{2}, \ldots$ and $\mathrm{V}_{\mathrm{n}}$, by boundaries, according to the degree of time for the plasma to be uniformly mixed with the dye. If the amount of the dye, $M$, injected into the plasma of volume $V_{1}$ transfers from $V_{1}$ to $V_{2}$, from $V_{2}$ to $V_{3}, \ldots$ and from $V_{n-1}$ to $V_{n}$ successively and is lost, in part, 


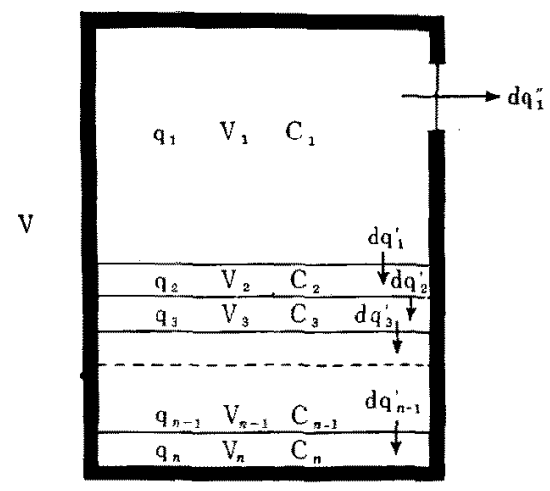

Fig. 8. Schematic representation of the n-compartment system of the total plasma of volume, $\mathrm{V}$.

from the blood vessels of volume $V_{1}$, mainly by the function of the reticulo-endothelial system, under the assumption that a number of units of the dye transfers by the concentration difference of two compartments facing the boundary and the dye contents are homogenous in each chamber, the transfer rate of a number of units of dye from each chamber at any time, $t$, is given by

$$
\begin{aligned}
& \frac{\mathrm{dq}^{\prime \prime}{ }_{1}}{\mathrm{dt}}=\mathrm{C}_{1} \mathrm{k}_{\mathrm{o}} \\
& \frac{\mathrm{dq_{1 } ^ { \prime }}}{\mathrm{dt}}=\left(\mathrm{C}_{1}-\mathrm{C}_{2}\right) \mathrm{k}_{1} \\
& \frac{\mathrm{dq}^{\prime}{ }_{2}}{\mathrm{dt}}=\left(\mathrm{C}_{2}-\mathrm{C}_{3}\right) \mathrm{k}_{2} \\
& \vdots \\
& \frac{\mathrm{d \textrm {d } ^ { \prime }}{ }^{\mathrm{n}-1}}{\mathrm{dt}}=\left(\mathrm{C}_{\mathrm{n}-1}-\mathrm{C}_{\mathrm{n}}\right) \mathrm{k}_{\mathrm{n}-1}
\end{aligned}
$$

where $\mathrm{dq}{ }_{1}$ is a number of units of dye transferred from $V_{1}$ to outside; $\mathrm{dq}_{1}{ }_{1}$, from $V_{1}$ to $V_{2} ; d_{q}^{\prime}$, from $V_{2}$ to $V_{3} ; \ldots$ and $d_{n-1}^{\prime}$, from $V_{n-1}$ to $V_{n}$; and $C_{1}, C_{2}, C_{3}, \ldots$ $\mathrm{C}_{\mathrm{n}-1}$ and $\mathrm{C}_{\mathrm{n}}$ are the concentrations of the dye in the compartments of $\mathrm{V}_{1}, \mathrm{~V}_{\mathrm{2}}$, $V_{3}, \ldots V_{n-1}$ and $V_{n}$, respectively. Here, $k_{o}, k_{1}, k_{2}, \ldots$ and $k_{n-1}$ are considered to be related to the character of each boundary and plasma flow in $V_{1}, V_{2}, V_{3}, \ldots$ and $\mathrm{V}_{\mathrm{n}-1}$, respectively. The rates of change in the number of units of dye, $\mathrm{q}_{1}, \mathrm{q}_{2}$, $\mathrm{q}_{3}, \ldots \mathrm{q}_{\mathrm{n}-1}$, and $\mathrm{q}_{\mathrm{n}}$, remaining in each chamber at any time $\mathrm{t}$ are expressed as :

$$
\begin{aligned}
& -\frac{\mathrm{dq}}{\mathrm{dt}}=\frac{\mathrm{dq}^{\prime \prime}{ }_{1}}{\mathrm{dt}}+\frac{\mathrm{dq}^{\prime}{ }_{1}}{\mathrm{dt}} \\
& \mathrm{dq}_{2}=\mathrm{dq}_{1}^{\prime} \quad \mathrm{dq}_{2}^{\prime} \\
& \mathrm{dt}=\mathrm{dt} d \mathrm{dt} \\
& \frac{\mathrm{dq}_{3}}{\mathrm{dt}}=\mathrm{dq}_{\mathrm{dt}}-\mathrm{dq}^{\prime}{ }_{3} \\
& \frac{\mathrm{dq}}{\mathrm{dt}}=\frac{\mathrm{dq}_{\mathrm{n}-1}^{\prime}}{\mathrm{dt}}
\end{aligned}
$$


Combining equations ( 1 ) and (2), and dividing equation (2) by $V_{1}, V_{2}, V_{3}, \ldots$ and $V_{n}$, to get the change in concentration per unit of time, we have:

$$
\begin{aligned}
\frac{\mathrm{dC}_{1}}{\mathrm{dt}} & =\left\{-\mathrm{C}_{1} \mathrm{k}_{0}-\left(\mathrm{C}_{1}-\mathrm{C}_{2}\right) \mathrm{k}_{1}\right\} / \mathrm{V}_{1} \\
\frac{\mathrm{dC_{2 }}}{\mathrm{dt}} & =\left\{\left(\mathrm{C}_{1}-\mathrm{C}_{2}\right) \mathrm{k}_{1}-\left(\mathrm{C}_{2}-\mathrm{C}_{3}\right) \mathrm{k}_{2}\right\} / \mathrm{V}_{2} \\
\frac{\mathrm{dC}}{\mathrm{dt}} & =\left\{\left(\mathrm{C}_{2}-\mathrm{C}_{3}\right) \mathrm{k}_{2}-\left(\mathrm{C}_{3}-\mathrm{C}_{4}\right) \mathrm{k}_{3}\right\} / \mathrm{V}_{3} \\
\vdots & \\
\frac{\mathrm{d} \mathrm{C}_{\mathrm{n}}}{\mathrm{dt}} & =\left(\mathrm{C}_{\mathrm{n}-1}-\mathrm{C}_{\mathrm{n}}\right) \mathrm{k}_{\mathrm{n}-1} / \mathrm{V}_{\mathrm{n}}
\end{aligned}
$$

As equation (3) gives linear differential equation of the $n$th order with constant coefficients, general solution for $\mathrm{C}_{1}$ is

$$
\mathrm{C}_{1}=\sum_{\mathrm{i}=1}^{\mathrm{n}} \mathrm{K}_{\mathrm{i}} \mathrm{e}^{-\mathrm{xit}}
$$

where $\mathrm{K}_{\mathbf{i}}$ is the constant of integration. This formula (4) is identical with equation (1) in the text.

Under the condition that $t=0$, equation (4) becomes:

$$
\mathrm{C}_{1}=\mathrm{K}_{1}+\mathrm{K}_{2}+\ldots+\mathrm{K}_{\mathrm{n}}
$$

Setting $C_{10}$ instead of $C_{1}$,

$$
\text { plasma volume } V_{1}=\frac{M}{C_{10}}
$$

For the special case of $n=2$, when the total plasma of volume $V$, was divided into the circulating plasma of volume $V_{1}$ and the sluggish one of volume $V_{2}$, equation (3) becomes

$$
\left.\begin{array}{l}
\frac{d C_{1}}{d t}=\left\{-C_{1} k_{o}-\left(C_{1}-C_{2}\right) k_{1} y / V_{1}\right. \\
\frac{d C_{2}}{d t}=\left(C_{1}-C_{2}\right) k_{1} / V_{2}
\end{array}\right\}
$$

Setting $k_{0} / V_{1}=k_{0}^{\prime}$ (disappearance coefficient) and $k_{1} / V_{2}=k_{1}^{\prime}$, equation (5) becomes :

$$
\left.\begin{array}{l}
\frac{\mathrm{dC}_{1}}{\mathrm{dt}}=-\mathrm{V}_{2}\left(\mathrm{C}_{1}-\mathrm{C}_{2}\right) \mathrm{k}_{1}^{\prime} / \mathrm{V}_{1}-\mathrm{C}_{1} \mathrm{k}_{0}^{\prime} \\
\frac{\mathrm{dC}_{2}}{\mathrm{dt}}=\left(\mathrm{C}_{1}-\mathrm{C}_{2}\right) \mathrm{k}_{1}^{\prime}
\end{array}\right\}
$$

Solving for $\mathrm{C}_{1}$

$$
\frac{\mathrm{d}^{2} \mathrm{C}_{1}}{\mathrm{dt}^{2}}+\frac{\mathrm{dC}_{1}}{\mathrm{dt}}\left\{\mathrm{k}^{\prime}{ }_{1}-\frac{\mathrm{V}_{1}+\mathrm{V}_{2}}{\mathrm{~V}_{1}}+\mathrm{k}_{0}^{\prime}{ }_{0}\right\}+\mathrm{k}^{\prime}{ }_{0} \mathrm{k}_{1}^{\prime} \mathrm{C}_{1}=0
$$

On integration, general solution for $\mathrm{C}_{1}$ is given by

$$
\mathrm{C}_{1}=\mathrm{K}_{1} \mathrm{e}^{+\mathrm{x}_{1} \mathrm{t}}+\mathrm{K}_{2} \mathrm{e}^{+\mathrm{x}_{3} \mathrm{t}}
$$


Here,

$$
\left.\begin{array}{l}
\mathrm{x}_{1}=-\frac{1}{2}\left(\mathrm{k}^{\prime}{ }_{1} \mathrm{~V}_{1}+\mathrm{V}_{2}+\mathrm{k}_{1}{ }_{0}\right)-\sqrt{\frac{1}{4}\left(\mathrm{k}^{\prime}{ }_{1} \mathrm{~V}_{1}+\mathrm{V}_{2}+\mathrm{V}_{1} \mathrm{k}_{0}\right)^{2}-\mathrm{k}^{\prime}{ }_{1} \mathrm{k}^{\prime}{ }_{0}} \\
\mathrm{x}_{2}=-\frac{1}{2}\left(\mathrm{k}^{\prime}{ }_{1} \frac{\mathrm{V}_{1}+\mathrm{V}_{2}}{\mathrm{~V}_{1}}+\mathrm{k}^{\prime}{ }_{0}\right)+\sqrt{\frac{1}{4}\left(\mathrm{k}^{\prime}{ }_{1} \frac{V_{1}+\mathrm{V}_{2}}{V_{1}}+\mathrm{k}^{\prime}{ }_{0}\right)^{2}-\mathrm{k}^{\prime}{ }_{1} \mathrm{k}^{\prime}{ }_{0}}
\end{array}\right\}
$$

Equation (7) shows that the concentration of the circulating plasma, $\mathrm{C}_{1}$, at any time, $t$, is expressed as a sum of two exponential curves. Circulating plasma volume $V_{1}$ is likewise gained from

$$
\mathrm{V}_{1}=\begin{aligned}
& \mathrm{M} \\
& \mathrm{C}_{10}
\end{aligned}
$$

where $M$ is the amount of injected dye, and $C_{10}$ is dye concentration at the time when $t=0$ in equation ( 7$)$. Differentiation of equation (7) gives

$$
\frac{\mathrm{dC}_{1}}{\mathrm{dt}}=\mathrm{x}_{1} \mathrm{~K}_{1} \mathrm{e}^{+\mathrm{r}_{1} \mathrm{t}}+\mathrm{x}_{2} \mathrm{~K}_{2} \mathrm{e}^{+\mathrm{x}_{2} \mathrm{t}}
$$

When $t=0$ in the combination of equations (6), (7) and (10), $C_{1}=C_{10}$ and $C_{2}=0$

$$
\begin{aligned}
& \mathrm{K}_{1}+\mathrm{K}_{2}=\mathrm{C}_{10} \\
& \mathrm{x}_{1} \mathrm{~K}_{1}+\mathrm{x}_{2} \mathrm{~K}_{2}=-\mathrm{C}_{10}\left(\mathrm{k}_{1}^{\prime} \mathrm{V}_{2} / \mathrm{V}_{1}+\mathrm{k}^{\prime}{ }_{0}\right)
\end{aligned}
$$

From the equation (11),

$$
\begin{aligned}
& \mathrm{K}_{1}=\mathrm{C}_{10}\left(\mathrm{k}_{1}^{\prime} \mathrm{V}_{2} / \mathrm{V}_{1}+\mathrm{k}^{\prime}{ }_{0}+\mathrm{x}_{2}\right) /\left(\mathrm{x}_{2}-\mathrm{x}_{1}\right) \\
& \mathrm{K}_{2}=\mathrm{C}_{10}\left(\mathrm{k}_{1}^{\prime} \mathrm{V}_{2} / \mathrm{V}_{1}+\mathrm{k}_{0}^{\prime}+\mathrm{x}_{1}\right) /\left(\mathrm{x}_{1}-\mathrm{x}_{2}\right)
\end{aligned}
$$

By using equations (11), (12), and $(9), V_{1} / V_{2}$ or $V_{1} / V$ can be calculated.

For the special case of $n=1$ where dye is lost from the blood stream after the completion of uniform mixing, equation (3) becomes

$$
\frac{\mathrm{dC}_{1}}{\mathrm{dt}}=-\mathrm{C}_{1} \mathrm{k}_{\mathrm{o}} / \mathrm{V}_{1}=-\mathrm{k}_{\mathrm{o}}^{\prime} \mathrm{C}_{1}
$$

which, on integration, gives

$$
\mathrm{C}_{1}=\mathrm{K}_{1} \mathrm{e}^{-\mathrm{k}^{\prime} \mathrm{o}^{\mathrm{t}}}
$$

To evaluate $K_{1}$, we have the condition that when $t=0, C_{1}=C_{10}$, which gives

$$
\mathrm{C}_{1}=\mathrm{C}_{10} \mathrm{e}^{-\mathrm{k}^{\prime} \mathrm{t}}
$$

\section{References}

1. Gregersen, M.I., and Rawson, R.A.: Am. J. Physiol. 138: 698, 1943.

2. Gibson, J.G., and Fvans, W.A.: J. Clin. Invest. 16: 301, 317, 1937.

3. Nakanishi, A. : Jap. Circulation J. 15: 19, 1951 (In Japanese).

4. Mikamo, Y., Kobayashi, T., and Nakanishi, A.: Ketsueki-gaku togikai hokoku 7: 155, 1954 (In Japanese).

5. Gregersen, M.I. : J. Lab. \& Clin. Med. 29 : 1266, 1944.

6. Miller, A.T. Jr.: Am. J. Physiol. 151 : 234, 1947.

7. Gilder, H., Müller, O.H., and Phillip, R.A.: Am. J. Physiol. 129: Proc. $362,1940$. 
8. Lawson, H.C., Overbey, D.T., Moore J.C., and Shadle, O.W.: Am. J. Physiol, 151: 282, 1947.

9. Cruickshank, E.W.H., and Whitfield, I.C.: J. Physiol. 104: 52, 1945.

10. Ferrebee, J.W., Leigh, O.C., and Berliner, R.W.: Proc. Soc. Exper. Biol. and Med. 46: 549, 1941.

11. Miller, A.T., Jr. : Am. J. Physiol. 151 : 229, 1947.

12. Allen, T.H., and Orahovats, P.D.: Am. J. Physiol. 154: 27, 1948.

13. Schultz, A.L., Hammarsten, J.F., Heller, B.I., and Ebert R.V.: J. Clin. Invest. 32: 107, 1953.

14. Unger, P.N., Zuckerbrod, M., Beck, G.J., and Steele, J.M. : J. Chin. Invest. 27: 111, 1948.

15. Erlanger, J.: Physiol. Rev. 1: 177, 1921.

16. Sunderman, F.W., and Austin, J.H. : Am. J. Physiol. 117: 474, 1936.

17. Price, P.B., and Longmire, W.P.: Bull. Johns Hopkins Hosp. 71 : 51, 1942.

18. Hahn, P.F., Ross, J.F., Bale, W.F., Balfour, W.M., and Whipple, G.H.: J. Exper. Med. 75 : 221, 1942.

19. Cruickshank, E.W.H., and Whitfield, I.C.: J. Physiol. 103: 19, 1944.

20. Allen, T.H., and Semple, R.E. : Am. J. Physiol. 165 : 205, 1951.

21. Rossiter, R.J.: Lancet, 156: 222, 1949.

22. Le Veen, H.H., and Fishman, W.H. : Am. J. Physiol. 151 : 26, 1947.

23. Rawson, R.A.: Am. J. Physiol. 151: 26, 1947. 